\title{
Effect of the polyphenol composition BP-C3 on haematological and intestinal indicators of 5-fluorouracil toxicity in mice
}

\author{
ANDREY V. PANCHENKO ${ }^{1}$, ELENA I. FEDOROS ${ }^{1,2}$, SERGEY E. PIGAREV ${ }^{2}$, \\ MIKHAIL A. MAYDIN ${ }^{1}$, EKATERINA A. GUBAREVA ${ }^{1}$, MARIA N. YUROVA ${ }^{1}$, GALINA S. KIREEVA ${ }^{1}$, \\ GALINA P. LANSKIKH ${ }^{1}$, MARGARITA L. TYNDYK ${ }^{1}$ and VLADIMIR N. ANISIMOV ${ }^{1}$ \\ ${ }^{1}$ Department of Carcinogenesis and Oncogerontology, N.N. Petrov National Medical Research Center of Oncology, \\ Saint-Petersburg $197758 ;{ }^{2}$ Nobel, Ltd., Saint-Petersburg 192012, Russia
}

Received June 16, 2017; Accepted November 9, 2017

DOI: $10.3892 / \mathrm{etm} .2018 .5782$

\begin{abstract}
BP-C3 is a formulation, which comprises lignin-derived polyphenolic composition of benzenepolycarboxylic acids (BP-CX-1) with iron complex, selenium, ascorbic acid and retinol, and possesses geroprotective activity. The present study examined the effect of BP-C3 $(80 \mathrm{mg} / \mathrm{kg}$, administered 18 times in total by gavage) on the development of haematological and intestinal manifestations of toxicity following 5-fluorouracil (5-FU; $150 \mathrm{mg} / \mathrm{kg}$, administered once via intravenous injection) administration in outbred male Swiss-H Rappolovo (SHR) mice. The use of BP-C3 on therapeutic and preventative/therapeutic schedules demonstrated that it was protective against the toxic effect of 5-FU exerted on the lymphopoietic organs. Administering BP-C3 $24 \mathrm{~h}$ after 5-FU (therapeutic schedule) had an effect on the recovery of leukopoiesis and prevented anaemia in the mice. In the mice that received 5-FU and 5-FU with $\mathrm{BP}-\mathrm{C} 3$ prior to and following administration of the chemotherapeutic agent (preventative/therapeutic schedule), mild anaemia developed by day 7. Administration of BP-C3 without 5-FU did not affect blood cell differentiation in the mice. Thus, BP-C3, depending on the administration schedule, had different effects on the haematological parameters of haematopoietic organs and peripheral blood in mice exposed to 5-FU. BP-C3 promoted intestinal crypt survival when administered on the preventative/therapeutic and therapeutic schedules, suggesting that the formulation protects the epithelium of the small intestine against damage by $5-\mathrm{FU}$.
\end{abstract}

Correspondence to: $\mathrm{Dr}$ Andrey V. Panchenko, Department of Carcinogenesis and Oncogerontology, N.N. Petrov National Medical Research Center of Oncology, 68 Leningradskaya Street, Saint-Petersburg 197758, Russia

E-mail: ando.pan@gmail.com

Key words: polyphenol composition BP-C3, benzenepolycarboxylic acids, 5-fluorouracil, chemotherapy, toxicity, blood count, intestinal crypt survival

\section{Introduction}

Anti-tumour chemotherapy using 5-fluorouracil (5-FU) and other cytostatics is often complicated by various disorders. Cellular damage caused by 5-FU is related to its intracellular transformation into 5-FU deoxynucleotide, which incorporates into RNA and interferes with RNA processing, and also inhibits thymidylate synthase enzyme, thereby affecting DNA synthesis and repair (1). 5-FU is effective against cancer of the digestive system (esophageal, stomach, intestinal, colon, pancreatic and liver cancer) and breast cancer (2). The toxicity of 5-FU is primarily associated with its effect on rapidly renewing tissues (those with high cellular turnover); the major dose-limiting factors are myelosuppression and damage to the gastrointestinal mucosa (3). Generation of reactive oxygen species (ROS) is the leading mechanism of the synergistic effect of polychemotherapeutic schemes incorporating 5-FU, causing disturbance of antioxidant enzymes (4), and is also one of the leading aspects in the development of mucositis (5).

An important aim of adjunct treatment in oncology patients is decreasing chemotherapy toxicity, since side effects lead to increased intervals between chemotherapy cycles or require dose reduction, and these changes have a negative effect on treatment results (6). The options for treating such disorders remain limited $(7,8)$. Ideally, medications used to correct toxic effects should not have side effects themselves, nor should they increase or decrease treatment effectiveness. Natural plant polyphenols are promising in this regard; they protect healthy tissues, in particular decreasing production of intracellular ROS, but do not diminish the effect of chemotherapies (9). Notably, not only low-molecular weight polyphenols exhibit antioxidant efficacy, but polymeric polyphenolic compositions, such as lignin derivatives, exert it too (10).

The present study examined the effect of BP-C3 on the development of haematological and intestinal manifestations of toxicity caused by the administration of high doses of 5-FU to mice. BP-C3 is a product, which comprises lignin-derived polyphenolic composition of benzenepolycarboxylic acids (BP-Cx-1) with iron complex, selenium, ascorbic acid and retinol. BP-Cx-1, produced through high-temperature alkaline hydrolysis of lignin conducted in the presence of air oxygen with subsequent isolation and purification (11), is 
used for preparation of medicinal products. Antineoplastic platinum-containing investigational medicinal product, $\mathrm{BP}-\mathrm{C} 1$, is used in clinical trials in patients with metastatic breast cancer (12). Investigational medicinal product, BP-C2, a composition of BP-Cx-1 with ammonium molybdate, inhibits radiation-induced skin damage in mice (13) and improves quality of life of patients with cancer treated with 5-FU-containing regimens (14). BP-C3, used in the present study, was previously demonstrated to exhibit geroprotective activity (15).

\section{Materials and methods}

Animals. A total of 105 outbred 2-month-old male Swiss-H-derived Rappolovo albino (SHR) mice were purchased from the Rappolovo Animal Facility (Rappolovo, Russia). The weight of animals at the commencement of the study was $31.0 \pm 2.2 \mathrm{~g}$. Animals were maintained in a $12-\mathrm{h}$ light/dark cycle at $21 \pm 2{ }^{\circ} \mathrm{C}$ with $20-50 \%$ average humidity and with ad libitum access to laboratory feed (Laborotorkorm Ltd., Moscow, Russia) and tap water. Study protocols were approved by the Local Ethics Committee of the N.N. Petrov National Medical Research Center of Oncology, previously known as N.N. Petrov Research Institute of Oncology (protocol no. 1 dated 13/02/2014; Saint-Petersburg, Russia). At the end of the study, the experimental animals were euthanized by trained personnel using $\mathrm{CO}_{2}$ inhalation.

Preparations. BP-C3 is a composition developed jointly by the N.N. Petrov Research Institute of Oncology and Nobel Ltd. (Saint-Petersburg, Russia) (16). BP-C3 is comprised of polyphenolic composition BP-Cx-1 (RD Innovation ApS, Copenhagen, Denmark), iron complex, selenium, ascorbic acid and retinol. BP-C3 composition was supplied by Nobel Ltd., as a $0.5 \%$ aqueous solution. 5-FU Ebewe (Sandoz International GmbH, Holzkirchen, Germany) concentrate for solution for infusions (50 mg/ml; batch no. EW4102) was used.

Experimental design. A total of 105 male SHR mice were randomly subdivided into five groups ( $n=21 /$ group). The mice in group 1, the control group, were given tap water by gavage as a placebo. The mice in groups 2, 3 and 4 were given a single intravenous injection of $5-\mathrm{FU}(150 \mathrm{mg} / \mathrm{kg})$, while the mice in groups 1 and 5 were injected with $0.9 \%$ saline solution on day 0 ). In addition, the mice in groups 3,4 , and 5 were gavaged with BP-C3 $(80 \mathrm{mg} / \mathrm{kg})$ daily except for day 0 (a total of 18 times). BP-C3 was administered on the preventative/therapeutic schedule in group 3, starting 7 days before the administration of 5-FU (day-7) and continuing through to day 11 , whereas in group 4 BP-C3 was given on the therapeutic schedule, starting on day 1 and continuing through to day 18 of the experiment.

The 5-FU dose level selected for the study is known to induce anemia in mice (17) and corresponds to dose levels that patients with cancer are exposed to; for example $500 \mathrm{mg} / \mathrm{m}^{2}$ in CAF regimen [cyclophosphamide, doxorubicin hydrochloride (Adriamycin) and 5-FU], which corresponds to $165 \mathrm{mg} / \mathrm{kg}$ dose in mice. The selected dose level was $<200 \mathrm{mg} / \mathrm{kg}$, which is the maximum tolerated single dose used in tumour-bearing mice (18). Animals were observed once daily, including weekends.
Blood count and bone marrow nucleated cell (BMNC) assay. Blood counts were examined in samples collected on day 0 before 5-FU administration and on days 4, 7, 11, 17 and 20. Blood samples (20-40 $\mu \mathrm{l})$ were taken from the tip of the tail and collected in test tubes (MiniCollect ${ }^{\circledR}$; Greiner Bio-One International $\mathrm{GmbH}$, Kremsmünster, Austria) containing $\mathrm{K}_{3}$ EDTA. Clinical blood analysis was performed on a Mindray BC-2800Vet Hematology Analyzer (Shenzhen Mindray Bio-Medical Electronics Co., Ltd, Shenzhen, China). On days 4, 11, and 20, 5 mice from each group were euthanized, and the cellular composition of the bone marrow was quantitatively analysed in a bone marrow cell suspension prepared by mixing of $0.02 \mathrm{ml}$ bone marrow aspirate with $0.4 \mathrm{ml}$ of a $3 \%$ acetic acid solution. BMNCs were counted using a haemocytometer (19).

Pathomorphology studies. In mice euthanized on day 4, the morphology of crypts in the small intestine was evaluated. At autopsy, the jejunum was taken and fixed in $10 \%$ buffered formalin at room temperature for $48 \mathrm{~h}$. Following fixation, 10 rings of $4-5 \mathrm{~mm}$ in height were dissected from each lymphoid-free intestinal sample. After routine histological processing, histological sections $4-\mu \mathrm{m}$ thick were prepared and stained with Mayer's haematoxylin $(8 \mathrm{~min}$ at room temperature) with subsequent differentiation and bluing and with eosin (30 sec at room temperature), dehydrated and mounted with xylene-based mounting medium. The survival of intestinal crypts was evaluated as described by Withers and Elkind (20), by counting the number of crypts (no fewer than 10 cells with basophilic nuclei lying next to each other) in at least six transverse cuts using a light microscope (Nikon Eclipse Ni-U, Nikon Corporation, Tokyo, Japan) at a magnification of x400 with NIS-Elements Br software (version 4.30.00; Nikon Corporation).

To evaluate the organ-specific toxic effect of 5-FU, the organ/body weight ratios of the spleen, thymus, heart, liver and kidneys were determined in animals euthanized on days 4, 11 and 20. At the autopsy the organs were dissected free of adhering tissue and weighed using Sartorius Research R 160 P (Sartorius AG, Gottingen, Germany). Organ/body weight (mg) ratio was multiplied by 10 and the mean absolute organ: Body weight ratios were calculated and compared.

Statistical analysis. Data were presented as the mean \pm standard error of the mean. SPSS (version 16.0; SPSS Inc., Chicago, IL, USA) was used to evaluate the data. Results were assessed by a two-way analysis of variance and Tukey's multiple comparisons test for 3-4 repeated measurements. $\mathrm{P}<0.05$ was considered to indicate a statistically significant difference.

\section{Results}

Survival of animals exposed to 5-FU. Evaluating survival was not within the scope of the study; however, there was some mortality observed among the mice, indicating that 5-FU had a toxic effect (Table I). On day 7, 6 experimental animals succumbed in group 2 (the group receiving 5-FU alone). The mortality in group 2 was significantly greater than that observed in the control group (29\% in group 2 vs. $0 \%$ in the control group; $\mathrm{P}<0.05$; Table I). The maximum weight 
Table I. Animal dropout rate during the experiment.

\begin{tabular}{lcccc}
\hline & \multicolumn{3}{c}{ Experiment day } & \\
\cline { 2 - 4 } Group & 4 & 11 & 20 & Dropout, \% \\
\hline 1. Control & $0(5)$ & $0(5)$ & $0(11)$ & 0 \\
2. 5-FU & $0(5)$ & $6^{\mathrm{a}}(5)$ & $0(5)$ & $29^{\mathrm{c}}$ \\
3. BP-C3 + 5-FU + BP-C3 & $0(5)$ & $1^{\mathrm{a}}(5)$ & $5^{\mathrm{b}}(5)$ & $29^{\mathrm{c}}$ \\
4. 5-FU + BP-C3 & $0(5)$ & $1^{\mathrm{a}}(5)$ & $0(10)$ & $5^{\mathrm{d}}$ \\
5. BP-C3 & $0(5)$ & $0(5)$ & $0(11)$ & 0 \\
\hline
\end{tabular}

Data are presented as number of dropouts (number euthanized according to protocol; $n=21$ ). ${ }^{a}$ Mortality occurred despite no clinical endpoints being observed at prior inspection; ${ }^{b} 2$ mice experienced mortality and 3 animals in a recumbent state were euthanized. ${ }^{c} \mathrm{P}<0.05$ vs. control group (Fisher's exact test). ${ }^{\mathrm{d}} \mathrm{P}=0.093$ vs. 5 -FU group (Fisher's exact test). 5-FU, 5-fluorouracil; BP-C3, lignin-derived polyphenolic composition of benzenepolycarboxylic acids, iron complex, selenium, ascorbic acid and retinol.

loss of the 6 animals that succumbed in group 2 was 3-16\%. Due to this, on the same day the remaining mice were weighed and a daily weighing of animals with body weight loss $>15 \%$ (6 animals in total) was introduced in the protocol. In group 3, 2 mice with $20 \%$ and 1 with $12 \%$ body weight loss found recumbent were euthanized. Additionally, 3 mice with a body weight loss of $17-20 \%$ and absent of clinical manifestations at the previous observation succumbed. In the group with preventative/therapeutic use of BP-C3 (group 3), the total dropout rate was also 29\%; dropouts in group 3 occurred 1-11 days later than those in group 2 . The mortality in the group with therapeutic BP-C3 regimen (commenced $24 \mathrm{~h}$ after 5-FU administration; group 4) was decreased to 5\% (1 mouse with $17 \%$ weight loss died at day $8 ; \mathrm{P}=0.093$ vs. group 2; Table I). Enteritis was identified as the primary macroscopic change in all dropout animals. Adverse events may develop rapidly in mice; therefore, more frequent inspection (i.e., twice-daily) of animals receiving 5-FU at doses starting at $150 \mathrm{mg} / \mathrm{kg}$ will be introduced in future protocols.

Dynamics of body weight of the animals. The toxic effect of 5-FU was manifested by the decreased body weight of the animals (average loss of $7 \%$ as of day 4). There was no significant difference in mean body weight of animals treated with 5-FU alone, and animals treated with a combination of 5-FU and BP-C3 (Table II). Body weight loss is a general sign of toxicity and is commonly $\sim 10 \%$ in animal studies evaluating cytostatic agents such as 5-FU (21). The maximum body weight loss registered in individual mice on day 4 was $-16,-11$ and $-10 \%$ of the initial body weight in the 5-FU (group 2), BP-C3 + 5-FU + BP-C3 (group 3) and 5-FU + BP-C3 (group 4) groups, respectively. The average body weight loss was transient and by day 11 no statistically significant differences between the experimental groups were present.

Organ/body weight ratios of the animals. To evaluate the organ-specific toxic effect of 5-FU, the organ/body weight ratios of the spleen, thymus, heart, liver and kidneys were determined (Table III). The spleen and thymus were the main organs that exhibited a toxic effect in response to 5-FU. The toxic effect was demonstrated by the significant decrease of the organ/body weight ratios of these organs on day 4 post 5 -FU administration compared with those observed in the control group $(\mathrm{P}<0.05)$. The use of BP-C3 in the therapeutic (group 4) and preventative/therapeutic (group 3) schedules was protective against the toxic effect that 5-FU exerted on the lymphopoietic organs.

Notably, by day 20 there was a significant increase in spleen weight in all groups that received 5-FU compared with that observed in the control group $(\mathrm{P}<0.05$; Table IIIA). Administration of BP-C3 affected this process. By day 11 the spleen/body weight ratio in animals treated with BP-C3 on the therapeutic schedule ( $24 \mathrm{~h}$ after exposure to $5-\mathrm{FU}$ ) was greater than that in the animals that received BP-C 3 on the preventative/therapeutic schedule. On day 20, the spleen/body weight ratio was reached the values observed in all groups where 5-FU was administered.

BP-C3 effects on 5-FU-induced hematological toxicity. The modification of the myelotoxic effect of 5-FU by co-administration of BP-C3 was evaluated (Fig. 1). The use of BP-C3 did not improve the 5-FU-induced suppression of bone marrow haematopoiesis that was observed on day 4. However, during the time that the BMNC count was recovering, there were differences in the effects of BP-C3 used on the therapeutic and preventative/therapeutic schedules. On day 11 , significantly fewer bone marrow nucleated cells were observed in group 4 compared with group $2(\mathrm{P}<0.05)$ and group $3(\mathrm{P}<0.01)$. However, on day 20 the BMNC count in group 4 was significantly greater compared with group $2(\mathrm{P}<0.05)$ and group 3 $(\mathrm{P}<0.01)$.

When blood counts were analysed, the following changes were noted (Table IV): Mice in groups 2, 3 and 4, which all received 5-FU, exhibited pronounced leukopenia on days 4 and 7, which changed to leukocytosis in groups 2 and 3 by days 14-17; however, this phenomenon was not reproduced in group 4. The changes in the populations of lymphocytes, granulocytes and monocytes were similar.

The lymphocyte count on day 4 in group 2 was $55 \%$ lower than that of the control group ( $\mathrm{P}<0.05$; Table IVA). By day 7 , the lymphocyte count in group 2 returned to a normal level. Although the lymphocyte count in group 2 was $38 \%$ lower compared with the control group on day 7 , no significant difference was identified. On day 14, the lymphocyte count in group 2 was significantly increased by $228 \%(\mathrm{P}<0.05)$ compared with the control group, followed by a decrease to the normal level by day 20 . The lymphocyte count in group 3 was reduced by $53 \%$ on day 4 and by $70 \%$ on day 7 compared with the control group at the respective time points (both $\mathrm{P}<0.05$ ), and thus this reduction lasted longer than that of group 2. On day 14 and 17 the lymphocyte count in group 3 increased significantly by 148 and $167 \%$, respectively ( $\mathrm{P}<0.05$ vs. the control group). In group 4 , the lymphocyte count decreased by $60 \%$ on day 4 and by $69 \%$ on day 7 (both $\mathrm{P}<0.05$ vs. control group).

Contrary to groups 2 and 3, no increase in lymphocyte count was observed in group 4 at later time points (between day 14 and 20). In groups 2,3 and 4, the granulocyte count 
Table II. Body weight of mice exposed to 5-FU with or without BP-C3.

\begin{tabular}{lccccr}
\hline \multirow{2}{*}{ Experiment day } & \multicolumn{5}{c}{ Body weight in each group, $\mathrm{c}$} \\
\cline { 2 - 6 } & 1. Control & 2.5 -FU & 3. BP-C3 + 5-FU + BP-C3 & 4. 5-FU + BP-C3 & 5. BP-C3 \\
\hline 0 & $31.66 \pm 0.49$ & $32.45 \pm 0.38$ & $32.01 \pm 0.48$ & $31.89 \pm 0.34$ & $32.27 \pm 0.46$ \\
4 & $32.34 \pm 0.65$ & $30.14 \pm 0.63^{\mathrm{a}, \mathrm{b}}$ & $30.39 \pm 0.47^{\mathrm{b}}$ & $30.13 \pm 0.43^{\mathrm{a}, \mathrm{b}}$ & $32.60 \pm 0.54$ \\
11 & $32.07 \pm 0.56$ & $32.62 \pm 0.50$ & $31.15 \pm 0.63$ & $32.11 \pm 0.61$ & $32.55 \pm 0.53$ \\
20 & $32.62 \pm 0.55$ & $33.76 \pm 0.61$ & $32.61 \pm 0.68$ & $33.26 \pm 0.2$ & $32.83 \pm 0.45$
\end{tabular}

${ }^{\mathrm{a}} \mathrm{P}<0.05$ vs. control group on the same day; ${ }^{\mathrm{b}} \mathrm{P}<0.05$ vs. BP-C 3 group on the same day. Values are presented as the mean \pm standard error of the mean. Data were analysed by a two-way analysis of variance. 5-FU, 5-fluorouracil; BP-C3, lignin-derived polyphenolic composition of benzenepolycarboxylic acids, iron complex, selenium, ascorbic acid and retinol.

(Table IVB) decreased by $\sim 80 \%$ on day 4 ( $\mathrm{P}<0.05$ vs. the control group). The decrease in the granulocyte count of $\sim 90 \%$ was most pronounced in groups 2,3 and 4 on day $7(\mathrm{P}<0.05$ vs. the control group). Differences between the groups 2, 3 and 4 were not statistically significant on day 7. At later time points, the granulocyte count significantly increased in group 2 by day 17 ( $\mathrm{P}<0.05$ vs. the control group), and in group 3 by day 14 and 17 (all $\mathrm{P}<0.05$ vs. the control group). In group 4 , no increase of the granulocyte count was observed on day 14 and 17 compared with the control group at the same time points.

The monocyte count significantly decreased on day 4 and 11 after 5-FU exposure in groups 2,3 and 4 (all $\mathrm{P}<0.05$ vs. the control group; Table IVC). At later time points, the monocyte count increased significantly on day 14 and 17 in group 2, and days $14-20$ in group 3 ( $\mathrm{P}<0.05$ vs. the control group). In group 4, a significant increase in the monocyte count was observed only on day 14 ( $\mathrm{P}<0.05$ vs. the control group) and was normalised by day 17 . In group 4 , the recovery of leukopoiesis without a pronounced stage of enhanced haematological response can be attributed to the anti-inflammatory effect of BP-C3, likely due to a shorter pro-inflammatory response of monocytes. Administration of BP-C3 without 5-FU did not have a significant effect on white blood cell differentiation in the mice.

Mild anaemia developed in the mice in group 2 between day 7 and 11, and in group 3 between day 11 and 14 as the red blood cell count significantly decreased at those time points in the aforementioned groups (all $\mathrm{P}<0.05$ vs. the control group; Table IVD). BP-C3 was administered $24 \mathrm{~h}$ after 5-FU to mice in group 4, which prevented the development of anaemia in the mice. Thus, BP-C3, depending on the administration schedule, has different effects on the haematological parameters of the haematopoietic organs and the peripheral blood.

BP-C3 effects on 5-FU-induced intestinal toxicity. As one of the primary manifestations of the toxic effect of 5-FU is enteritis, the number of surviving intestinal crypts following exposure to 5-FU was evaluated. Histological examination of samples, collected on day 4 from all mice treated with 5-FU, identified the death of crypts, shortening or loss of the villi and a chronic inflammatory response in the intestinal mucosa. The counts of the surviving crypts are demonstrated in Fig. 2. The number of crypts per intestinal cross-section decreased significantly

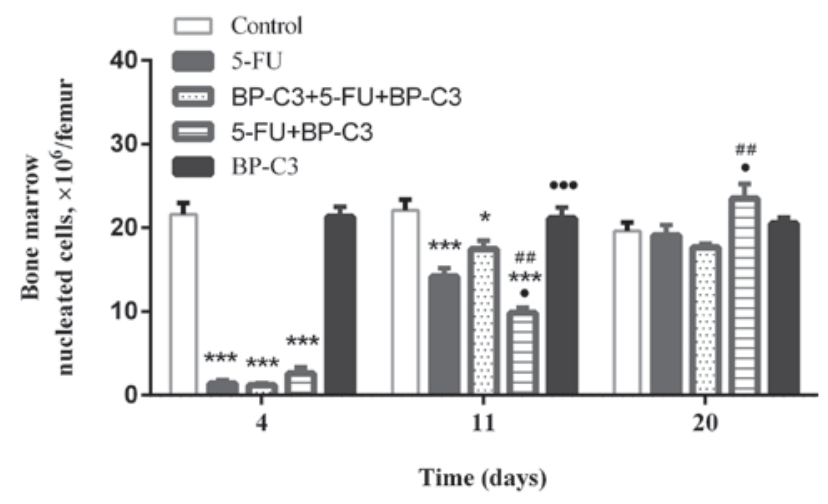

Figure 1. Changes in the bone marrow nucleated cell count in Swiss-H-derived Rappolovo albino mice exposed to $150 \mathrm{mg} / \mathrm{kg} 5$-FU. Values are presented as the mean \pm standard error of the mean. ${ }^{*} \mathrm{P}<0.05$ and ${ }^{* * *} \mathrm{P}<0.001$ vs. the control group; ${ }^{\# \#} \mathrm{P}<0.01$ vs. the $\mathrm{BP}-\mathrm{C} 3+5-\mathrm{FU}+\mathrm{BP}-\mathrm{C} 3$ group; ${ }^{\circ} \mathrm{P}<0.05$ and $\cdots \mathrm{P}<0.001$ vs. the 5 -FU group. 5-FU, 5-fluorouracil; BP-C3, lignin-derived polyphenolic composition of benzenepolycarboxylic acids, iron complex, selenium, ascorbic acid and retinol.

in group 2 ( $\mathrm{P}<0.01$ vs. the control group). By contrast, BP-C3 promoted intestinal crypt survival when administered on either the preventative/therapeutic (group 3; $\mathrm{P}<0.05$ vs. group 2) or the therapeutic (group 4; $\mathrm{P}<0.01$ vs. group 2) schedule. BP-C3 treatment alone (group 5) did not affect number of surviving intestinal crypts. In summary, BP-C3 protects the epithelium of the small intestine against damage induced by 5 -FU.

\section{Discussion}

Substances of plant origin, polyphenols in particular, are promising chemotherapy adjuncts for several reasons. First, they have low toxicity and cause essentially no side effects, as opposed to the synthetic drugs that are currently used in clinical practice to decrease chemotherapy side effects (22). Second, various compounds in this chemical group have been demonstrated to have their own anti-tumour activity. Polyphenol compounds slow the growth of various cancer cell lines and also inhibit carcinogenesis in vivo (23-25). Various plant agents, including genistein, curcumin, epigallocatechin gallate, resveratrol and proanthocyanidin, are able to potentiate the effectiveness of traditional chemotherapeutic drugs (22). 
Table III. The effect of BP-C3 on 5-FU-induced changes in organ/body weight ratios.

A, Spleen

\begin{tabular}{llll}
\hline & \multicolumn{3}{c}{ Organ/body weight ratio on each experiment day, mg/10 g } \\
\cline { 2 - 4 } Group & 4 & 11 & 20 \\
\hline 1. Control & $36.39 \pm 3.01$ & $38.43 \pm 2.83$ & $37.11 \pm 5.41$ \\
2. 5-FU & $16.57 \pm 1.55^{\mathrm{a}}$ & $45.10 \pm 6.66^{\mathrm{b}}$ & $88.96 \pm 5.02^{\mathrm{a}, \mathrm{c}}$ \\
3. BP-C3 + 5-FU + BP-C3 & $23.89 \pm 2.67$ & $54.95 \pm 10.31^{\mathrm{b}, \mathrm{c}}$ & $95.02 \pm 2.77^{\mathrm{a}, \mathrm{c}}$ \\
4. 5-FU + BP-C3 & $36.31 \pm 2.00$ & $92.92 \pm 9.81^{\mathrm{a}, \mathrm{c}}$ & $80.80 \pm 5.21^{\mathrm{a}, \mathrm{c}}$ \\
5. BP-C3 & $35.86 \pm 5.10$ & $30.75 \pm 0.65$ & $35.38 \pm 1.78$
\end{tabular}

B, Thymus

\begin{tabular}{llll}
\hline & \multicolumn{3}{c}{ Organ/body weight ratio on each experiment day, mg/10 g } \\
\cline { 2 - 4 } Group & 4 & 11 & 20 \\
\hline 1. Control & $22.26 \pm 2.79$ & $22.21 \pm 1.45$ & $20.60 \pm 0.65$ \\
2. 5-FU & $14.01 \pm 1.10^{\mathrm{a}}$ & $18.44 \pm 2.39$ & $20.39 \pm 1.61$ \\
3. BP-C3 + 5-FU + BP-C3 & $18.90 \pm 3.76$ & $21.02 \pm 1.47$ & $21.16 \pm 2.25$ \\
4. 5-FU + BP-C3 & $16.21 \pm 1.06$ & $15.88 \pm 1.23$ & $17.16 \pm 1.21$ \\
5. BP-C3 & $19.51 \pm 2.63$ & $22.62 \pm 1.53$ & $20.98 \pm 1.03$ \\
\hline C, Heart & & & \\
\hline
\end{tabular}

\begin{tabular}{lccr} 
& \multicolumn{3}{c}{ Organ/body weight ratio on each experiment day, mg/10 g } \\
\cline { 2 - 4 } Group & 4 & 11 & 20 \\
\hline 1. Control & $66.23 \pm 8.99$ & $66.13 \pm 6.66$ & $64.64 \pm 3.85$ \\
2. 5-FU & $63.10 \pm 4.28$ & $52.64 \pm 2.57$ & $56.23 \pm 1.37$ \\
3. BP-C3 + 5-FU + BP-C3 & $56.90 \pm 3.59$ & $64.93 \pm 9.11$ & $57.87 \pm 2.17$ \\
4. 5-FU + BP-C3 & $55.12 \pm 2.57$ & $64.24 \pm 5.31$ & $55.82 \pm 2.73$ \\
5. BP-C3 & $66.88 \pm 6.60$ & $60.73 \pm 4.05$ & $60.58 \pm 2.61$ \\
\hline
\end{tabular}

D, Liver

\begin{tabular}{lcrr}
\hline & \multicolumn{3}{c}{ Organ/body weight ratio on each experiment day, $\mathrm{mg} / 10 \mathrm{~g}$} \\
\cline { 2 - 4 } Group & 4 & 11 & 20 \\
\hline 1. Control & $594.38 \pm 54.71$ & $605.24 \pm 46.98$ & $541.53 \pm 19.14$ \\
2. 5-FU & $475.70 \pm 13.77$ & $472.04 \pm 26.63$ & $509.56 \pm 26.22$ \\
3. BP-C3 + 5-FU + BP-C3 & $595.79 \pm 24.40$ & $545.28 \pm 40.06$ & $576.07 \pm 30.38$ \\
4. 5-FU + BP-C3 & $540.68 \pm 39.11$ & $590.89 \pm 48.13$ & $511.19 \pm 33.71$ \\
5. BP-C3 & $600.78 \pm 69.93$ & $541.90 \pm 31.40$ & $552.30 \pm 35.96$ \\
\hline
\end{tabular}

E, Kidney (left)

\begin{tabular}{lccr}
\hline & \multicolumn{3}{c}{ Organ/body weight ratio on each experiment day, $\mathrm{mg} / 10 \mathrm{~g}$} \\
\cline { 2 - 4 } Group & 4 & 11 & 20 \\
\hline 1. Control & $83.14 \pm 7.72$ & $89.56 \pm 8.51$ & $77.76 \pm 3.74$ \\
2. 5-FU & $88.18 \pm 8.92$ & $80.58 \pm 6.00$ & $69.26 \pm 6.07$ \\
3. BP-C3 + 5-FU + BP-C3 & $79.40 \pm 3.36$ & $86.12 \pm 2.71$ & $71.84 \pm 3.79$
\end{tabular}


Table III. Continued.

E, Kidney (left)

Organ/body weight ratio on each experiment day, mg/10 g

Group

4

11

20

4. 5-FU + BP-C3

$75.43 \pm 5.35$

$70.95 \pm 3.74$

$67.10 \pm 2.97$

5. BP-C3

$79.40 \pm 3.36$

$86.12 \pm 2.71$

$71.84 \pm 3.79$

${ }^{\mathrm{a}} \mathrm{P}<0.05$ vs. control group on the same day; ${ }^{\mathrm{b}} \mathrm{P}<0.05$ vs. $5-\mathrm{FU}+\mathrm{BP}-\mathrm{C} 3$ group on the same day; ${ }^{\mathrm{C}}<0.05$ vs. BP-C 3 group on the same day. Values are presented as the mean \pm standard error of the mean. Data were analysed by a two-way analysis of variance. 5-FU, 5-fluorouracil; BP-C3, lignin-derived polyphenolic composition of benzenepolycarboxylic acids, iron complex, selenium, ascorbic acid and retinol.

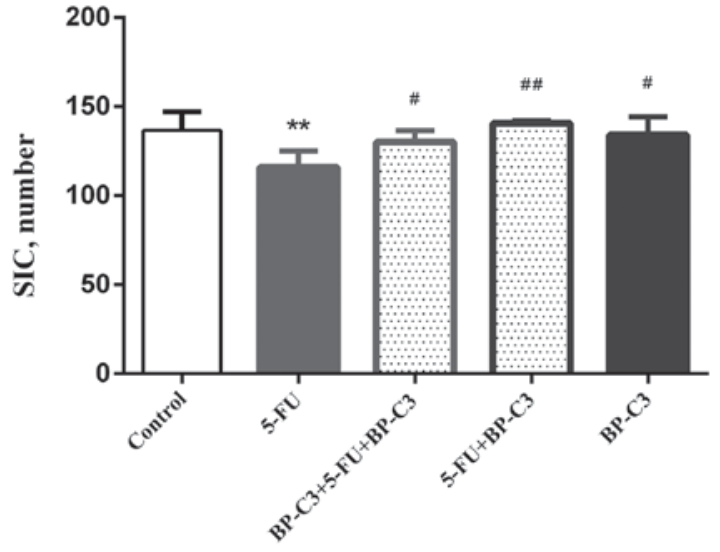

Figure 2. Number of SICs in the small intestine of the mice on day 4 post 5-FU administration. Values are presented as mean \pm standard error of the mean. ${ }^{* *} \mathrm{P}<0.01$ vs. the control; ${ }^{\#} \mathrm{P}<0.05$ and ${ }^{\# \#} \mathrm{P}<0.01$ vs. 5 -FU. SIC, surviving intestinal crypts; 5-FU, 5-fluorouracil; BP-C3, lignin-derived polyphenolic composition of benzenepolycarboxylic acids, iron complex, selenium, ascorbic acid and retinol.

In the cell, polyphenols bind to numerous targets, neutralise free radicals and affect numerous signalling pathways, including the epigenetic regulation of gene expression and mitochondrial function (26). Oxidative stress is one of the mechanisms of action of various anti-tumour substances; therefore, the effectiveness of chemotherapy may be modulated by substances with antioxidant properties. Some of the most common exogenous antioxidants are polyphenolic compounds, which protect us from developing cardiovascular diseases, diabetes, cancer and infectious diseases (27). Antioxidants may protect normal tissue without affecting the effectiveness of anti-tumour chemotherapeutic drugs $(28,29)$. Paradoxically, polyphenols exert an antioxidant effect on healthy cells, while in cancer cells they increase free radicals, causing cellular aging, cell cycle arrest and apoptosis (30). In the presence of copper ions, of which there are more in cancer cells than in normal cells (31), at least some polyphenols (luteolin, apigenin, epigallocatechin-3-gallate and resveratrol) act as pro-oxidants. The anti-tumour effect of these polyphenols decreases significantly in the presence of copper chelators (32).

Polyphenols reduce toxic effects on normal tissues, thus quercetin protects normal renal tubular cells from drug toxicity and attenuates drug-induced nausea and vomiting (22). Traditional Japanese medicines have been demonstrated to protect intestinal epithelium during 5-FU use (33). Besides their direct antioxidant effect, vegetable and fruit flavonoids are able to increase the activity of detoxifying enzymes (34).

Notably, various investigational drugs are traditional medicines, also known as multi-component mixtures, and their various constituents possibly potentiate one another. For example, experiments in mice exposed to $\gamma$ radiation have demonstrated that the mixtures of polyphenols of green tea were more protective than the tea's individual components (35). Although such traditional medicines are effective, lack of sufficient standardisation is their drawback.

Polyphenol substances exert anti-tumour effects through other mechanisms as well. Curcumin, a polyphenol of plant origin, has numerous molecular effects; in particular, it suppresses the transcription of nuclear factor- $\kappa \mathrm{B}$, and affects the receptors of various growth factors and cell adhesion molecules involved in tumour growth, angiogenesis and metastasis (36). Curcumin has a radioprotective or radiosensitising effect, depending on the dose, and these effects are now being actively studied to support the use of this product as an adjunct therapy for radio and chemotherapy (37). Thus, preparations that contain various polyphenols may be considered as promising adjunct therapies for oncology patients.

The use of such substances in oncology patients may improve quality of life and overall survival, particularly in palliative patients. The results of previous study on BP-C2, administered from week 2-26 in combination with a FOLFIRINOX regimen in a patient with inoperable pancreatic cancer, indicated that during treatment no neutropenia developed for 18 weeks, and blood biochemistry normalised by week 25 (14). In a long-term study performed in female SHR mice, the mean life span increased by $\sim 50$ days in animals treated with BP-C3 compared with the untreated control group (15). A greater number of tumour-free mice and delayed age-related switch-off of the oestrus function were observed, possibly due to immunomodulatory effect of BP-C3 (15).

Thus, the findings from the present study, which demonstrate the protective effects of BP-C3 on the immune system and other systems, and intestinal epithelium, are in line with and complement the results of previous studies 
Table IV. The effect of BP-C3 on 5-FU-induced changes in white and red blood cell counts.

A, Lymphocytes, $10^{9} / 1$

\begin{tabular}{lccccccc}
\hline & \multicolumn{7}{c}{ Experiment day } \\
\cline { 2 - 8 } Group & 0 & 4 & 7 & 11 & 14 & 17 & 20 \\
\hline 1. Control & $5.99 \pm 0.94$ & $6.18 \pm 0.55$ & $8.08 \pm 0.76$ & $6.40 \pm 0.99$ & $6.71 \pm 0.55$ & $6.77 \pm 1.07$ & $5.44 \pm 0.65$ \\
2. 5-FU & $5.61 \pm 0.65$ & $2.79 \pm 0.37^{\mathrm{a}, \mathrm{b}}$ & $5.02 \pm 1.17$ & $10.60 \pm 1.24$ & $22.02 \pm 5.94^{\mathrm{a}, \mathrm{b}}$ & $13.54 \pm 3.50^{\mathrm{b}}$ & $7.72 \pm 3.24$ \\
3. BP-C3 + 5-FU + BP-C3 & $5.96 \pm 0.69$ & $2.90 \pm 0.48^{\mathrm{a}, \mathrm{b}}$ & $2.45 \pm 0.49^{\mathrm{a}, \mathrm{b}}$ & $7.51 \pm 1.31$ & $16.63 \pm 3.15^{\mathrm{a}-\mathrm{c}}$ & $18.18 \pm 3.95^{\mathrm{a}, \mathrm{b}}$ & $10.06 \pm 0.97$ \\
4. 5-FU + BP-C3 & $6.07 \pm 0.52$ & $2.48 \pm 0.15^{\mathrm{a}}$ & $2.52 \pm 0.38^{\mathrm{a}, \mathrm{b}}$ & $6.87 \pm 1.98$ & $8.68 \pm 1.30$ & $11.64 \pm 1.41$ & $5.94 \pm 2.27$ \\
5. BP-C3 & $5.61 \pm 1.03$ & $5.82 \pm 0.75$ & $6.50 \pm 0.59$ & $5.70 \pm 0.81$ & $5.43 \pm 1.47$ & $4.10 \pm 0.65$ & $4.03 \pm 1.19$ \\
\hline
\end{tabular}

B, Granulocytes, $10^{9} / 1$

\begin{tabular}{|c|c|c|c|c|c|c|c|}
\hline \multirow[b]{2}{*}{ Group } & \multicolumn{7}{|c|}{ Experiment day } \\
\hline & 0 & 4 & 7 & 11 & 14 & 17 & 20 \\
\hline 1. Control & $4.88 \pm 0.37$ & $4.44 \pm 0.29$ & $4.71 \pm 0.84$ & $3.97 \pm 0.41$ & $4.54 \pm 0.60$ & $4.39 \pm 0.96$ & $4.20 \pm 0.64$ \\
\hline 2. 5-FU & $4.29 \pm 0.35$ & $1.95 \pm 0.27^{\mathrm{a}, \mathrm{b}}$ & $0.58 \pm 0.13^{\mathrm{a}, \mathrm{b}}$ & $3.65 \pm 0.63$ & $12.04 \pm 2.75$ & $16.98 \pm 7.93^{\mathrm{a}, \mathrm{b}}$ & $8.74 \pm 2.09$ \\
\hline 3. $\mathrm{BP}-\mathrm{C} 3+5-\mathrm{FU}+\mathrm{BP}-\mathrm{C} 3$ & $4.14 \pm 0.30$ & $1.46 \pm 0.15^{\mathrm{a}, \mathrm{b}}$ & $0.41 \pm 0.09^{\mathrm{a}, \mathrm{b}}$ & $3.84 \pm 0.61$ & $21.00 \pm 6.93^{\mathrm{a}-\mathrm{c}}$ & $19.54 \pm 8.25^{\mathrm{a}-\mathrm{c}}$ & $9.34 \pm 1.83$ \\
\hline 4. $5-\mathrm{FU}+\mathrm{BP}-\mathrm{C} 3$ & $4.22 \pm 0.59$ & $1.08 \pm 0.28^{\mathrm{a}, \mathrm{b}}$ & $0.40 \pm 0.06^{\mathrm{a}, \mathrm{b}}$ & $3.68 \pm 1.17$ & $7.58 \pm 0.85$ & $8.44 \pm 1.00$ & $5.44 \pm 0.87$ \\
\hline 5. BP-C3 & $3.80 \pm 0.42$ & $3.32 \pm 0.24$ & $3.82 \pm 0.65$ & $3.57 \pm 0.34$ & $3.73 \pm 0.38$ & $2.88 \pm 0.51$ & $2.45 \pm 0.34$ \\
\hline
\end{tabular}

C, Monocytes, $10^{9} / 1$

\begin{tabular}{|c|c|c|c|c|c|c|c|}
\hline \multirow[b]{2}{*}{ Group } & \multicolumn{7}{|c|}{ Experiment day } \\
\hline & 0 & 4 & 7 & 11 & 14 & 17 & 20 \\
\hline 1. Control & $0.58 \pm 0.04$ & $0.63 \pm 0.08$ & $0.64 \pm 0.13$ & $0.52 \pm 0.06$ & $0.51 \pm 0.09$ & $0.54 \pm 0.12$ & $0.60 \pm 0.12$ \\
\hline 2.5-FU & $0.47 \pm 0.04$ & $0.19 \pm 0.03^{\mathrm{a}, \mathrm{b}}$ & $0.15 \pm 0.03^{\mathrm{a}, \mathrm{b}}$ & $0.60 \pm 0.21$ & $2.26 \pm 0.22^{\mathrm{a}-\mathrm{c}}$ & $1.58 \pm 0.36^{\mathrm{a}, \mathrm{b}}$ & $0.94 \pm 0.22$ \\
\hline 3. $\mathrm{BP}-\mathrm{C} 3+5-\mathrm{FU}+\mathrm{BP}-\mathrm{C} 3$ & $0.44 \pm 0.04$ & $0.16 \pm 0.03^{\mathrm{a}, \mathrm{b}}$ & $0.11 \pm 0.03^{\mathrm{a}, \mathrm{b}}$ & $0.79 \pm 0.11$ & $2.37 \pm 0.39^{\mathrm{a}-\mathrm{c}}$ & $2.07 \pm 0.30^{\mathrm{a}-\mathrm{c}}$ & $1.46 \pm 0.15^{\mathrm{a}-\mathrm{c}}$ \\
\hline 4. 5-FU + BP-C3 & $0.38 \pm 0.07$ & $0.12 \pm 0.04^{\mathrm{a}, \mathrm{b}}$ & $0.1 \pm 0.03^{\mathrm{a}, \mathrm{b}}$ & $0.74 \pm 0.23$ & $1.38 \pm 0.17^{\mathrm{a}, \mathrm{b}}$ & $0.98 \pm 0.26$ & $0.48 \pm 0.09$ \\
\hline 5. BP-C3 & $0.43 \pm 0.06$ & $0.44 \pm 0.04$ & $0.52 \pm 0.10$ & $0.43 \pm 0.04$ & $0.40 \pm 0.04$ & $0.50 \pm 0.20$ & $0.25 \pm 0.06$ \\
\hline
\end{tabular}

D, Red blood cells, $10^{12} / 1$

\begin{tabular}{|c|c|c|c|c|c|c|c|}
\hline \multirow[b]{2}{*}{ Group } & \multicolumn{7}{|c|}{ Experiment day } \\
\hline & 0 & 4 & 7 & 11 & 14 & 17 & 20 \\
\hline 1. Control & $10.7 \pm 0.3$ & $10.4 \pm 0.2$ & $10.6 \pm 0.3$ & $10.5 \pm 0.2$ & $9.9 \pm 0.4$ & $10.0 \pm 0.3$ & $9.9 \pm 0.2$ \\
\hline 2.5-FU & $11.0 \pm 0.3$ & $10.7 \pm 0.3$ & $8.9 \pm 0.5^{\mathrm{a}-\mathrm{c}}$ & $8.5 \pm 0.5^{\mathrm{a}, \mathrm{b}}$ & $9.5 \pm 0.3$ & $10.2 \pm 0.4$ & $10.5 \pm 0.4$ \\
\hline 3. $\mathrm{BP}-\mathrm{C} 3+5-\mathrm{FU}+\mathrm{BP}-\mathrm{C} 3$ & $11.1 \pm 0.2$ & $10.7 \pm 0.4$ & $9.5 \pm 0.4$ & $8.1 \pm 0.2^{\mathrm{a}, \mathrm{b}}$ & $8.4 \pm 0.2^{\mathrm{a}, \mathrm{b}}$ & $9.4 \pm 0.1$ & $9.8 \pm 0.4$ \\
\hline 4. $5-\mathrm{FU}+\mathrm{BP}-\mathrm{C} 3$ & $11.4 \pm 0.3$ & $11.4 \pm 0.3$ & $10.5 \pm 0.4$ & $9.4 \pm 0.8$ & $8.8 \pm 0.3$ & $9.5 \pm 0.2$ & $9.2 \pm 0.3$ \\
\hline 5. BP-C3 & $10.7 \pm 0.2$ & $10.3 \pm 0.2$ & $10.7 \pm 0.3$ & $10.7 \pm 0.3$ & $10.5 \pm 0.3$ & $10.7 \pm 0.3$ & $10.7 \pm 0.1$ \\
\hline
\end{tabular}

${ }^{\mathrm{a}} \mathrm{P}<0.05$ vs. control group on the same day; ${ }^{\mathrm{P}}<0.05 \mathrm{vs}$. BP-C3 group on the same day; ${ }^{\mathrm{c}} \mathrm{P}<0.05$ vs. $5-\mathrm{FU}+\mathrm{BP}-\mathrm{C} 3$ group on the same day. Values are presented as the mean \pm standard error of the mean. Data were analysed by a two-way analysis of variance. 5-FU, 5-fluorouracil; BP-C3, lignin-derived polyphenolic composition of benzenepolycarboxylic acids, iron complex, selenium, ascorbic acid and retinol.

by our group, though molecular mechanisms underlying these effects remain to be further elucidated. Future studies to assess the potential of BP-C3 in combination with certain chemotherapy agents and regimens will allow the identification of optimal combinations, doses and dosing schedules. 
The experimental data of the present study extends current knowledge on the biological activity of lignin-derived polyphenolic compositions, which are a group of natural compounds. The extensive therapeutic potential of lignin-derived polyphenolic compositions is yet to be explored. The present study demonstrated the feasibility of using a lignin-derived polyphenolic composition to diminish the toxic effects of chemotherapy, in particular, to reduce the haematological and gastrointestinal adverse effects.

\section{Acknowledgements}

The present study was supported by a grant from the Russian Science Foundation (grant no. 16-15-00142 to VNA).

\section{References}

1. Santi DV, McHenry CS and Sommer H: Mechanism of interaction of thymidylate synthetase with 5-fluorodeoxyuridylate. Biochemistry 13: 471-481, 1974.

2. Nair KL, Jagadeeshan S, Nair SA and Kumar GV: Biological evaluation of 5-fluorouracil nanoparticles for cancer chemotherapy and its dependence on the carrier, PLGA. Int J Nanomedicine 6: 1685-1697, 2011

3. Poon MA, O'Connell MJ, Moertel CG, Wieand HS, Cullinan SA, Everson LK, Krook JE, Mailliard JA, Laurie JA, Tschetter LK, et al: Biochemical modulation of fluorouracil: Evidence of significant improvement of survival and quality of life in patients with advanced colorectal carcinoma. J Clin Oncol 7: 1407-1418, 1989

4. Matsunaga T, Tsuji Y, Kaai K, Kohno S, Hirayama R, Alpers DH, Komoda T and Hara A: Toxicity against gastric cancer cells by combined treatment with 5-fluorouracil and mitomycin c: Implication in oxidative stress. Cancer Chemother Pharmacol 66: 517-526, 2010

5. Leitão RFC, Ribeiro RA, Bellaguarda EA, Macedo FD, Silva LR, Oriá RB, Vale ML, Cunha FQ and Brito GA: Role of nitric oxide on pathogenesis of 5-fluorouracil induced experimental oral mucositis in hamster. Cancer Chemother Pharmacol 59: 603-612, 2007.

6. Braun MS and Seymour MT: Balancing the efficacy and toxicity of chemotherapy in colorectal cancer. Ther Adv Med Oncol 3 : 43-52, 2011.

7. Ribeiro RA, Wanderley CW, Wong DV, Mota JM, Leite CA, Souza MH, Cunha FQ and Lima-Júnior RC: Irinotecan- and 5-fluorouracil-induced intestinal mucositis: Insights into pathogenesis and therapeutic perspectives. Cancer Chemother Pharmacol 78: 881-893, 2016.

8. You JS, Chen JP, Chan JS, Lee HF, Wong MK, Yeung WF and Lao LX: Effect of YH0618 soup on chemotherapy-induced toxicity in patients with cancer who have completed chemotherapy: Study protocol for a randomized controlled trial Trials 17: 354, 2016.

9. Coccia A, Mosca L, Puca R, Mangino G, Rossi A and Lendaro E: Extra-virgin olive oil phenols block cell cycle progression and modulate chemotherapeutic toxicity in bladder cancer cells Oncol Rep 36: 3095-3104, 2016.

10. Qazi SS, Li D, Briens C, Berruti F and Abou-Zaid MM: Antioxidant activity of the lignins derived from fluidized-bed fast pyrolysis. Molecules 22: pii: E372, 2017.

11. Shipov VP, Pigarev ES and Fedoros EI: Benzene polycarboxylic acid compounds and their use as drug: Patent WO2013143549 A1. Filed April 2, 2013; issued October 3, 2013.

12. Larsen S, Butthongkomvong K, Manikhas A, Trishkina E, Poddubuskaya E, Matrosova M, Srimuninnimit V and Lindkær-Jensen S: BP-C1 in the treatment of patients with stage IV breast cancer: A randomized, double-blind, placebo-controlled multicenter study and an additional open-label treatment phase. Breast Cancer (Dove Med Press) 6: $179-189,2014$

13. Fares F, Fares B, Azzam N, Nashashibi M, Nevelsky A, Larsen S and Lindkær-Jensen S: An innovative complex of benzene-poly-carboxylic acid and molybdenum, for prevention and treatment of radiation dermatitis. Med Chem 5: 447-451, 2015.
14. Ibrahim T, Larsen S, Jensen NHL and Lindkær-Jensen S: BP-C2 improves functional status, quality of life and corrects biochemical imbalances as adjuvant therapy to FOLFIRINOX treatment: A case of advanced inoperable pancreatic cancer. J Clin Case Rep 5: 514, 2015.

15. Anisimov VN, Popovich IG, Zabezhinski MA, Yurova MN, Tyndyk ML, Anikin IV, Egormin PA, Baldueva IA, Fedoros EI, Pigarev SE and Panchenko AV: Polyphenolic drug composition based on benzenepolycarboxylic acids (BP-C3) increases life span and inhibits spontaneous tumorigenesis in female SHR mice. Aging (Albany NY) 8: 1866-1875, 2016.

16. Anisimov VN,ZabezhinskiMA,Popovich IG,Tyndyk ML,Anikin IV, Egormin PA, Yurova MN, Piskunova TS, Panchenko AV, Shipov VP, et al; N.N. Petrov Research Institute of Oncology, Nobel Ltd.: Pharmacological geroprotective composition and method of obtaining thereof. Russian patent RU 2522547, 2014.

17. Tian Y, Xiang Y, Wan G, Wan D, Zhu H, Wang T and Yang X: Effects and mechanisms of Bazhen decoction, Siwu decoction and Sijunzi decoction on 5-fluorouracil-induced anemia in mice. J Tradit Chin Med 36: 486-495, 2016.

18. Vershinina SF and Stukov AN (eds): Handbook of experimental therapy of tumours. FGU RSCRST and FGU RIO n.a. NN Petrov of the FAHTMC of Russian Federation, Reprint LLC, Saint-Petersburg, p25, 2008 (In Russian).

19. Mcculloch EA and Till JE: The radiation sensitivity of normal mouse bone marrow cells, determined by quantitative marrow transplantation into irradiated mice. Radiat Res 13: 115-125, 1960.

20. Withers HR and Elkind MM: Microcolony survival assay for cells of mouse intestinal mucosa exposed to radiation. Int J Radiat Biol Relat Stud Phys Chem Med 17: 261-267, 1970.

21. Coronado-Cerda EE, Franco-Molina MA, Mendoza-Gamboa E, Prado-García H, Rivera-Morales LG, Zapata-Benavides P, Rodríguez-Salazar Mdel C, Caballero-Hernandez D, Tamez-Guerra RS and Rodríguez-Padilla C: In vivo chemoprotective activity of bovine dialyzable leukocyte extract in mouse bone marrow cells against damage induced by 5 -fluorouracil. J Immunol Res 2016: 6942321, 2016.

22. Sak K: Chemotherapy and dietary phytochemical agents. Chemother Res Pract 2012: 282570, 2012.

23. Katiyar SK, Mohan RR, Agarwal R and Mukhtar H: Protection against induction of mouse skin papillomas with low and high risk of conversion to malignancy by green tea polyphenols. Carcinogenesis 18: 497-502, 1997.

24. Kubatka P,Kapinová A, Kello M,Kruzliak P,Kajo K, Výbohová D, Mahmood S, Murin R, Viera T, Mojžiš J, et al: Fruit peel polyphenols demonstrate substantial anti-tumour effects in the model of breast cancer. Eur J Nutr 55: 955-965, 2016.

25. Mileo AM and Miccadei S: Polyphenols as modulator of oxidative stress in cancer disease: New therapeutic strategies. Oxid Med Cell Longev 2016: 6475624, 2016.

26. Barrajón-CatalánE,Herranz-LópezM,JovenJ,Segura-CarreteroA, Alonso-Villaverde C, Menéndez JA and Micol V: Molecular promiscuity of plant polyphenols in the management of age-related diseases: Far beyond their antioxidant properties. Adv Exp Med Biol 824: 141-159, 2014.

27. Mut-Salud N, Álvarez PJ, Garrido JM, Carrasco E, Aránega A and Rodríguez-Serrano F: Antioxidant intake and antitumor therapy: Toward nutritional recommendations for optimal results. Oxid Med Cell Longev 2016: 6719534, 2016.

28. Lamson DW and Brignall MS: Antioxidants in cancer therapy; their actions and interactions with oncologic therapies. Altern Med Rev 4: 304-329, 1999.

29. Lawenda BD, Kelly KM, Ladas EJ, Sagar SM, Vickers A and Blumberg JB: Should supplemental antioxidant administration be avoided during chemotherapy and radiation therapy? J Natl Cancer Inst 100: 773-783, 2008.

30. Mileo AM and Miccadei S: Polyphenols as modulator of oxidative stress in cancer disease: New therapeutic strategies. Oxid Med Cell Longev 2016: 6475624, 2016.

31. Gupte A and Mumper RJ: Elevated copper and oxidative stress in cancer cells as a target for cancer treatment. Cancer Treat Rev 35: 32-46, 2009.

32. Khan HY, Zubair H, Faisal M, Ullah MF, Farhan M, Sarkar FH, Ahmad A and Hadi SM: Plant polyphenol induced cell death in human cancer cells involves mobilization of intracellular copper ions and reactive oxygen species generation: A mechanism for cancer chemopreventive action. Mol Nutr Food Res 58: 437-446, 2014. 
33. Kato S, Hayashi S, Kitahara Y, Nagasawa K, Aono H, Shibata J, Utsumi D, Amagase K and Kadowaki M: Saireito (TJ-114), a Japanese traditional herbal medicine, reduces 5-fluorouracil-induced intestinal mucositis in mice by inhibiting cytokine-mediated apoptosis in intestinal crypt cells. PLoS One 10: e0116213, 2015.

34. Liska DJ: The detoxification enzyme systems. Altern Med Rev 3: 187-198, 1998

35. Lee HJ, Kim JS, Moon C, Kim JC, Lee YS, Jang JS, Jo SK and Kim SH: Modification of gamma-radiation response in mice by green tea polyphenols. Phytother Res 22: 1380-1383, 2008.
36. Wilken R, Veena MS, Wang MB and Srivatsan ES: Curcumin: A review of anti-cancer properties and therapeutic activity in head and neck squamous cell carcinoma. Mol Cancer 10: 12, 2011.

37. Hejazi J, Rastmanesh R, Taleban FA, Molana SH, Hejazi E, Ehtejab G and Hara N: Effect of curcumin supplementation during radiotherapy on oxidative status of patients with prostate cancer: A double blinded, randomized, placebo-controlled study. Nutr Cancer 68: 77-85, 2016. 